\title{
Pneumocystis cell wall $\beta$-glucan stimulates calcium-dependent signaling of IL-8 secretion by human airway epithelial cells
}

\author{
Eva M Carmona, Jeffrey D Lamont, Ailing Xue, Mark Wylam and Andrew H Limper*
}

\begin{abstract}
Background: Respiratory failure secondary to alveolar inflammation during Pneumocystis pneumonia is a major cause of death in immunocompromised patients. Neutrophil infiltration in the lung of patients with Pneumocystis infection predicts severity of the infection and death. Several previous studies indicate that airway epithelial cells release the neutrophil chemoattractant proteins, MIP-2 (rodents) and IL-8 (humans), in response to Pneumocystis and purified Pneumocystis cell wall $\beta$-glucans (PCBG) through the NF-kB-dependent pathway. However, little is known about the molecular mechanisms that are involved in the activation of airway epithelium cells by PCBG resulting in the secretion of IL-8.
\end{abstract}

Method: To address this, we have studied the activation of different calcium-dependent mitogen-activated protein kinases (MAPKs) in 1 HAEo- cells, a human airway epithelial cell line.

Results: Our data provide evidence that PCBG induces phosphorylation of the MAPKs, ERK, and p38, the activation of NF-KB and the subsequently secretion of IL-8 in a calcium-dependent manner. Further, we evaluated the role of glycosphingolipids as possible receptors for $\beta$-glucans in human airway epithelial cells. Preincubation of the cells with D-threo-1-phenyl-2-decanoylamino-3-morpholino-1-propanol (PDMP) a potent inhibitor of the glycosphingolipids synthesis, prior to PCBG stimulation, significantly decreased IL-8 production.

Conclusion: These data indicate that PCBG activates calcium dependent MAPK signaling resulting in the release of IL-8 in a process that requires glycosphingolipid for optimal signaling.

\section{Introduction}

Pneumocystis pneumonia is an opportunistic infection, caused by Pneumocystis jirovecii that predominantly affects immunosuppressed patients, including those with AIDS and malignancy. With the introduction of the highly active retroviral therapy (HAART) the incidence of Pneumocystis pneumonia among the HIV-infected patients has decreased significantly, but still remains among the most common severe opportunistic infection in this group of patients [1]. In addition, in non-HIV immunocompromised patients Pneumocystis infection is associated with substantially greater morbidity and mor-

\footnotetext{
* Correspondence: limper.andrew@mayo.edu

1 From the Thoracic Diseases Research Unit, Division of Pulmonary Critical Care and Internal Medicine, Department of Medicine Mayo Clinic and Foundation, Rochester, Minnesota, 55905, USA

Full list of author information is available at the end of the article
}

tality when compared with HIV-positive population despite the available medication [2].

It has been postulated that one reason for the differential mortality rates between the two groups is based on the differing abilities to mount inflammatory responses in the face of infection; with non-HIV-infected patients having a more robust inflammatory response against the organism is elicited compared to HIV-infected individuals. Indeed, this exuberant inflammatory reaction towards the organism has been shown to be more harmful to the host than the organism burden itself [3-5]. Polymorphonuclear neutrophils (PMN) are one of the major components of the lung inflammatory reaction seen in patients affected with Pneumocystis pneumonia, though CD8 cells and other cells are known to participate as well [6-8]. Moreover, it has been documented that the degree of neutrophil infiltration in the lung of these patients can 
serve as a marker of the severity of respiratory failure and death [3-5,9]. From theses observations, we have further postulated that a balanced inflammatory response is necessary to successfully control Pneumocystis infection.

Pneumocystis organisms are present within the alveolus in at least two different developmental stages, namely the trophic form and the cyst. The trophic form attaches firmly to the alveolar epithelium, in a process that stimulates organism proliferation [10]. The cyst form is characterized by a thick $\beta$-glucan rich cell wall, which recent studies have implicated as a major initiator of lung inflammation during Pneumocystis infection $[11,12]$. However, the molecular mechanisms by which $\beta$-glucans induce this exaggerated airway inflammatory response have not yet been fully elucidated.

Airway epithelial cells actively participate in the immune response during infection, not only by recognizing the microorganisms, but also by initiating appropriate signal transduction pathways that will lead to the production of a variety of cytokines and chemokines involved in the recruitment of inflammatory cells to the site of infection. In the case of Pneumocystis, various studies have demonstrated that Pneumocystis organisms closely associate with airway epithelial cells; supporting the tenant that binding of the organism to airway epithelial cells is an integral component in the establishment of infection $[13,14]$. While Pneumocystis trophic forms bind preferentially to Type I alveolar cells, Pneumocystis cysts and degraded components can be found in expectorated sputum [15]. Thus, Pneumocystis components such as glucan have ample opportunity to interact with epithelial cells in the lower respiratory tract.

Our group has demonstrated that fungal $\beta$-glucans in the wall of Pneumocystis induce NF- $\mathrm{kB}$ translocation and TNF- $\alpha$ production in macrophages following contact with the phagocyte [16]. In addition, we have also demonstrated that Pneumocystis $\beta$-glucans (PCBG) stimulate rat airway epithelial cells to secrete macrophage inflammatory protein-2 (MIP-2) through NF- $\mathrm{kB}$ dependent mechanisms $[17,18]$. However, the events through which PCBG initiate airway epithelial cells activation remain unclear. Various bacterial pathogens such as Salmonella and Pseudomonas species activate epithelial cells by increasing intracellular calcium concentrations $[19,20]$. For instance, during pseudomonal infection, superficial interactions of the microbe with airway epithelial cells are sufficient to induce changes in calcium influx and subsequently stimulate NF-kB-dependent gene expression [19]. We, therefore, hypothesized that following binding of PCBG to airway epithelial cells, the epithelial cells are stimulated to express pro-inflammatory responses by inducing changes in cytosolic calcium influx. These changes in intracellular calcium subsequently activate major signal transduction pathways that eventually lead to cytokine secretion by airway epithelial cells.

Fungal adhesion to host tissues is an integral step for colonization and subsequent infection $[10,21,22]$. Histological studies of Pneumocystis infected patients and animals demonstrate intimate association of Pneumocystis organisms with alveolar epithelial cells [13]. Many receptors have been proposed to bind Pneumocystis particles including dectin-1, $\beta 2$ integrin $C D 11 \mathrm{~b} / \mathrm{CD} 18$, and lactosylceramide $[16,17,23,24]$. Airway epithelial cells specifically lack dectin-1 receptors, which are present in macrophages. Based on our recent observations demonstrating that lactosylceramide is responsible for MIP-2 production, we further evaluated the role of glycosphingolipids in cytokine signaling by airway epithelial cells activated with PCBG $[17,18]$.

Herein, we demonstrate that $1 \mathrm{HAEo}^{-}$human airway epithelial cells simulated with PCBG induce the release of the neutrophil chemokine IL-8, in a calcium-dependent manner. We further demonstrate the participation of two major MAPKs, ERK and p38, and that at least two major transcription factors, NF- $\mathrm{KB}$ and AP-1, are necessary for an adequate transcription of IL-8. Finally, we observed that glycosphingolipids are necessary for the synthesis of IL- 8 by PCBG activated $1 \mathrm{HAEo}^{-}$cells.

\section{Materials and methods \\ Reagents and antibodies}

Endotoxin-free buffers and reagents were scrupulously employed for all experiments. Saccharomyces cerevisiae derived cell wall $\beta$-glucans, the calcineurin disrupting agents TEMPO (2,2,6,6-Tetramethyl-1-piperidinyloxy, free radical, 2,2,6,6-Tetramethylpiperidine 1-oxyl) and cyclosporin B were purchased from Sigma Chemical Co, (St. Louis, MO). The calcium chelator BAPTA/AM (1,2bis-(o-Aminophenoxy)-ethane-N,N,N',N'-tetraacetic acid, tetraacetoxymethyl ester) was obtained from Alexis Biochemical. The glucosylceramide synthase inhibitor PDMP (D-threo-1-Phenyl-2-decanoylamino-3-morpholino-1-propanol. $\mathrm{HCl}$ ) was purchased from Matreya, LLC (Pleasant Gap, PA), LPS from Escherichia coli 026:B6, EGTA, PD 98059, SB 202190, SB 202474, JNK inhibitor II and other general reagents were from Calbiochem (Gibbstown, NJ), unless otherwise specified. Pneumocystis carinii was derived originally from the American Type Culture Collection stock (Manassas, VA) and has been passaged though our immunosuppressed rat colony [25]. All antibodies employed in these studies were purchased from Cell Signaling Technologies (Danvers, MA). The human airway epithelial cell line, 1HAEocells, were generously provided by Dr. Dieter Gruenert (University of California, San Francisco) [26]. The cells were routinely cultured in Modified Eagle's medium con- 
taining $10 \%$ fetal bovine serum and $2 \mathrm{mM}$ L-glutamine, penicillin 10,000 units/liter, and streptomycin $1 \mathrm{mg} /$ liter.

\section{Plasmids}

The NF-kB-dependent firefly luciferase reporter expression vector (kB-luc) was a kind gift of Dr. Carlos Paya (Mayo Clinic, Rochester, MN)[27]. The IL-8, IL-8 mutated in AP-1, and NF-kB sites promoter-luciferase reporter plasmids were gifts from Dr. Marc Hershenson (University of Michigan)[28]. The pRL-TK expression vector, which provides constitutive expression of Renilla luciferase, was purchased from Promega (Madison, Wisconsin).

\section{Generation of Pneumocystis carinii $\beta$-Glucan-rich Cell Wall Isolate}

The Mayo Institutional Animal Care and Usage Committee approved all animal experimentation. A $\beta$-glucan-rich cell wall fraction from $P$. carinii was prepared as we previously described $[11,18]$. Pneumocystis pneumonia was induced in dexamethasone-treated immunosuppressed Lewis rats (Harlan, Inc., Indianapolis, IN) [25]. Pneumocystis organisms were isolated from lungs of heavily infected animals by homogenization and filtration through $10-\mu \mathrm{m}$ filters. The organisms were autoclaved $\left(120^{\circ} \mathrm{C}, 20 \mathrm{~min}\right)$ and disrupted by ultrasonication $(200 \mathrm{~W}$ for $3 \mathrm{~min}$, six times), and the glucans were isolated by $\mathrm{NaOH}$ digestion and lipid extraction as previously detailed $[11,18]$. As we prior reported, the final product contained predominantly carbohydrate (95.7\%) and released $82 \%$ of its content as D-glucose following hydrolysis [11]. Extensive measures were employed to ensure that the fractions were free of endotoxin. Prior to use in culture, the Pneumocystis cell wall fractions were washed with $0.1 \%$ SDS and then vigorously washed with distilled physiological saline to remove the detergent. The final preparation was assayed for endotoxin with the Limulus amebocyte lysate assay method and found to consistently contain $<0.125$ units of endotoxin [11].

\section{IL-8 detection}

IL-8 was measured in the supernatants of cultivated $1 \mathrm{HAEo}^{-}$cells by ELISA (BD OptEIA ${ }^{\mathrm{m}}, \mathrm{BD}$ biosciences, San Diego, CA). Cells were cultured to $\sim 70 \%$ confluence in a 96-well plates. Prior to activation with PCBG, the cells were weaned from serum for 18 hours. For some experiments, the cells were preincubated with various calcium disrupting agents or MAPKs inhibitors for one hour prior to stimulation. Supernatant was collected after 8 hour of stimulation with PCBG unless otherwise indicated and stored at $-70^{\circ} \mathrm{C}$. All experiments were performed in duplicate and repeated on a minimum of at least three occasions.

\section{Cellular Viability}

Cell viability was confirmed using the XTT Cell Proliferation Kit II (Roche Molecular Biochemicals, Mannheim, Germany). This assay measures the conversion of sodium-3'-[1-(phenylaminocarbonyl)-3,4-tetrazolium]bis(4-methoxy-6-nitro) benzenesulfonic acid hydrate (XTT) to a formazan dye through electron coupling in metabolically active mitochondria using the coupling reagent $N$-methyldibenzopyrazine methyl sulfate. Only metabolically active cells are capable of mediating this reaction, which is detected by absorbance of the dye at 450-500 $\mathrm{nm}$. Greater than 80\% survival was considered acceptable cellular viability in all the experiments.

\section{Intracellular calcium flux determination using digital video fluorescence imaging}

To measure intracellular $\mathrm{Ca}^{2+}$ fluxes, cells were plated in 8 well borosilicate coverglass chambers and were incubated with $5 \mu \mathrm{M}$ Fura-2AM (acetoxy-methyl-2-[5-[bis[(acetoxymethoxy-oxomethyl)methyl]amino]-4-[2-[2-

[bis[(acetoxymethoxy-oxo methyl)methyl]amino]-5methyl-phenoxy]-ethoxy]benzofuran-2-yl] oxazole-5-carboxylate, a calcium imaging dye that binds to free $\mathrm{Ca}^{2+}$ in HBSS (Hanks balanced salt solution with $2.25 \mathrm{mM} \mathrm{CaCl}_{2}$, $0.8 \mathrm{mM} \mathrm{MgSO}_{4}$ and $12 \mathrm{mM}$ glucose; $\mathrm{pH}$ 7.4) for $60 \mathrm{~min}$ utes at room temperature. Cells were then washed twice with fresh HBSS and subsequently maintained in HBSS. Cells were continuously perfused during the acquisition of $\mathrm{Ca}^{2+}$ measurements. Fluorescence excitation, image acquisition, and $\mathrm{Ca}^{2+}$ data analyses were controlled using a dedicated video fluorescence imaging system (Metafluor; Universal Imaging Corporation). Cells were imaged using an inverted Nikon Diaphot microscope equipped with a Nikon Fluor X20 objective lens. Fura 2-loaded cells were alternately excited at 340 and $380 \mathrm{~nm}$ using a Lambda 10-2 filter changer (Sutter Instrument Company). Fluorescence emissions were collected separately for each wavelength using a $510 \mathrm{~nm}$ barrier filter. Images were acquired using a Micromax 12 bit camera system (Princeton Instruments) approximately every $0.75 \mathrm{sec}-$ onds. Intracellular $\mathrm{Ca}^{2+}$ concentrations were calculated from the ratio of intensities at $340 \mathrm{~nm}$ and $380 \mathrm{~nm}$, by extrapolation from a calibration curve as previously described [29]. For a positive control of intracellular calcium release, cells were stimulated in parallel with PAR-2 Peptide (Anaspec, San Jose, Ca (Protease activated receptor - 2)) at a final concentration of $100 \mu \mathrm{M}$.

\section{Cell extraction and immunoblotting}

To obtain total cellular proteins, cells were washed with cold phosphate-buffered saline (PBS) twice and lysed in RIPA buffer (50 mM Tris- $\mathrm{HCl} \mathrm{pH} 7.4,15 \mathrm{mM} \mathrm{NaCl}$, $0.25 \%$ deoxycholic acid, 1\% NP-40, 1 mM EDTA) freshly 
supplemented with $2 \mu \mathrm{M}$ phenylmethylsulfonyl fluoride [PMSF], $10 \mu \mathrm{g} / \mathrm{ml}$ aprotinin, $1 \mu \mathrm{g} / \mathrm{ml}$ leupeptin, $1 \mu \mathrm{g} / \mathrm{ml}$ pepstatin, $10 \mathrm{mM} \mathrm{NaF}$ and $300 \mu \mathrm{M} \mathrm{Na}$ orthovanadate. Cell lysates were centrifuged at $12,000 \times g$ for $1 \mathrm{~min}$ at $4^{\circ} \mathrm{C}$. The resultant supernatant contained total cellular protein. Protein concentrations in the clarified supernatants were determined using the Bio-Rad (Hercules, Calif.) protein assay. For Western immunoblotting, equal amounts of total cellular proteins were separated by $10 \%$ SDS-PAGE and transferred to Immobilon-P membranes (Millipore, Bedford, Mass.). Immunoblotting was performed with specific antibodies and visualized using the ECL enhanced chemiluminescence Western blotting detection kit (Amersham, Buckinghamshire, England). Densitometry analysis of the Immunoblots was performed using the computer program Image $1.42 \mathrm{~d}$, National Institutes of Health, USA. The data was expressed as fold increase of the ratio between the protein of interest and the loading control.

\section{Gene transfection and reporter assays}

Cells were seeded in 24-well plates. Lipofectamine Plus (Invitrogen) was used to transfect DNA plasmids into the $1 \mathrm{HAEO}^{-}$cells according to the manufacturer's protocol. Following trasfection, the 1HAEo-cells were cultured for an additional 12 to 18 hours. Next, the cells were stimulated for eight hours with PCBG $(100 \mu \mathrm{g} / \mathrm{ml})$. One hour prior to stimulation, the cells were pretreated with PD98059 (16 $\mu \mathrm{M})$, SB202190 (30 $\mu \mathrm{M})$, JNK inhibitor II $(10 \mu \mathrm{M})$ or BAPTA $(1.2 \mu \mathrm{M})$. Following stimulation, the cells were washed twice in cold PBS and lysed with 50$100 \mu \mathrm{l}$ of lysis buffer (Promega dual-luciferase reporter assay system). Firefly and Renilla luciferase activities from $10 \mu \mathrm{l}$ of cell extracts were assayed with the Promega dual-luciferase reporter assay system reagents and a Berthold Lumat following the manufacturer's protocol. The $\kappa$ B-luc and IL-8 luc activities were normalized for Renilla expression. All transfection experiments were performed in duplicate.

\section{Effects of glycosphingolipids inhibitors on PCBG induced IL-8 secretion and ERK phosphorylation by airway epithelial cells}

Cells were cultured as previously described, and incubated with PDMP to reduce glycosphingolipid concentration, or media alone, for 72 hours prior to PCBG stimulation. Phosphorylation of p44/42 was analyzed from total cell lysates by immunoblotting and IL- 8 was measured by ELISA in the culture supernatant. To exclude toxicity to the airway epithelial cells induced by PDMP, XTT viability assays were performed under identical conditions. Greater than $80 \%$ viability was considered as acceptable cellular viability for all experimental conditions.

\section{Statistical and data analyses}

All data are shown as the means \pm SEM, unless otherwise stated. Data were assessed for significance using the Student $t$ test or ANOVA with relevant posttests where appropriate. Statistical differences were considered to be significant if $p$ was $<0.05$. Statistical analysis was performed using GraphPad Prism version 5 (GraphPad Software, La Jolla, CA).

\section{Results}

\section{PCBG induce IL-8 secretion from 1HAEo-cells}

Since patients with severe Pneumocystis pneumonia exhibit an intense neutrophil infiltration in their lungs, we postulated that airway epithelial cells might participate in IL-8 secretion and subsequent recruitment of inflammatory cells in response to infection [5,30,31]. Our prior studies have been performed in rat primary alveolar epithelial cells [17]. However, such primary cell cultures are of rodent origin and, as primary cultures, have limited ability to evaluate signaling pathways and promoter mechanisms. Therefore, in this investigation we utilized the 1HAEo-human airway epithelial cell line. Accordingly, we first determined whether IL-8 was secreted by 1 HAEo-airway epithelial cells challenged with either PCBG or $S$. cerevisiae derived $\beta$-glucans. The $1 \mathrm{HAEo}^{-}$ cells were exposed to the fungal $\beta$-glucan preparations, or LPS, and IL-8 release was measured after 14 hours of challenge. P. carinii and to a lesser degree Saccharomyces derived $\beta$-glucans induced IL-8 secretion in a dosedependent manner compared with both unstimulated and LPS challenged cells (Figure 1). Significantly, the absence of response of these cells to LPS excluded the possibility that endotoxin contamination of the $\beta$-glucan preparation was responsible for the observed inflammatory responses.

\section{IL-8 secretion by airway epithelial cells stimulated with PCBG is calcium-dependent}

Since various microbial ligands are able to initiate intracellular calcium fluxes during cell stimulation, we next investigated whether PCBG challenge of airway epithelial cells triggered intracellular calcium release [31,32]. Consistent with this, we observed that PCBG-treated cells release intracellular calcium within a few seconds of stimulation (Figure 2A). As a positive control, a potent PAR-2 agonist peptide was tested in parallel. The peak wave of calcium release in PCBG treated cells appeared to be somewhat slower and maybe more prolonged than in PAR-2 treated cells. We believe that this is explained by the differences in formulation between the two compounds. While PAR-2 is a soluble reagent, and likely acts quicker on the cells, PCBG is a particulate agonist with slower action time. 


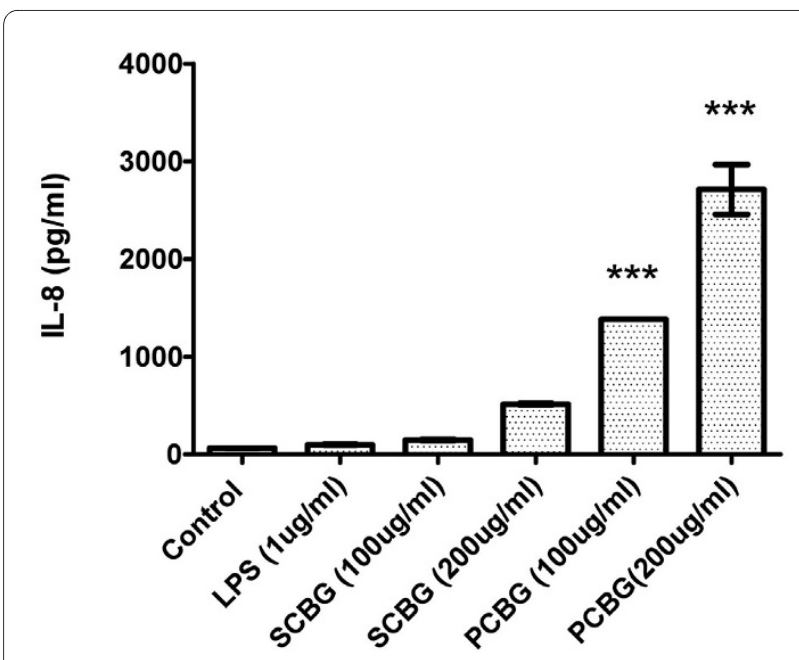

Figure 1 PCBG induces IL-8 release from 1HAEo- human airway epithelial cells. Cells were incubated with LPS, Saccharomyces cerevisiae $\beta$-glucan and Pneumocystis $\beta$-glucan at the indicated doses for a period of 14 hours. Release of IL-8 was measured by ELISA in the media supernatant of the cells. Data were analyzed with one-way ANOVA and posttest Dunnett's comparison test (*** denotes $p<0.001)$. The experiment shown is representative of three independent experiments.

Next, we sought to evaluate the importance of calcium release in IL-8 secretion of PCBG stimulation of 1HAEoepithelial cells. Accordingly, cells were pretreated with various calcium-signaling disrupting agents prior to PCBG stimulation and IL-8 release was determined in the culture supernatants, after 8 hours of stimulation (Figure $2 \mathrm{~B}$ and $2 \mathrm{C}$ ). Cells pretreated with EGTA, an extracellular calcium chelator [33], did not demonstrate any decrease in IL-8 secretion. In contrast, epithelial cells preincubated with the intracellular chelator BAPTA/AM [34], the calcineurin disrupting agents TEMPO, or cyclosporin A [35] each demonstrated significant decrease in IL-8 production (Figure $2 \mathrm{~B}$ and $2 \mathrm{C}$ ). Together, these data indicate that optimal secretion of IL-8 by airway epithelial cells stimulated with PCBG requires intra-cellular, rather than extra-cellular, calcium mobilization.

\section{IL-8 secretion by airway epithelial cells is mediated by NF- $\mathrm{KB}$ and AP-1}

A variety of transcription factors including NF- $\kappa B$ and AP-1 binding sites have been identified within the IL-8 promoter [36-42]. These transcription factors bind the promoter as dimers, and various combinations of AP-1 and NF- $\mathrm{kB}$ have been shown to be important for optimal activation of the IL- 8 promoter, particularly in epithelial cells [43]. Therefore, to further investigate the importance of NF- $\mathrm{kB}$ and AP-1, in IL-8 production induced by $\beta$-glucans, we measured IL- 8 activation in 1 HAEo-cells transiently transfected with the IL-8 luciferase reporter construct or with an IL-8 luciferase reporter construct that had targeted mutations in the NF- $\mathrm{kB}$ or AP-1 bind- ing sites (Figure 3). PCBG failed to activate IL-8 transcription in cells transfected with either the mutant NF$\mathrm{kB}$ or mutant AP-1 constructs, whereas IL-8 transcription was activated normally in cells transfected with the wild-type IL- 8 promoter construct. From these observations, we can imply that both transcription factors are necessary for optimal activation of IL- 8 transcription by airway epithelial cells following stimulation with PCBG.

\section{IL-8 secretion by PCBG stimulated airway epithelial cells is mediated by MAP Kinases}

Since MAPKs has been implicated in IL- 8 secretion by airway epithelial cells, we next investigated whether MAPK activation was necessary for $\beta$-glucan stimulation of airway epithelial cells to release IL-8 [31,44,45]. To accomplish this, $1 \mathrm{HAEo}^{-}$cells were preincubated with PD98059, a specific pharmacological inhibitor of ERK, prior to stimulation with PCBG. Cells pre-treated with PD98059 exhibited a dose-dependent decrease in IL-8 production in response to the PCBG compared with untreated cells (Figure 4A). To further understand the kinetics of MAPK/ERK activation phosphorylation of ERK was determined by western immunoblotting after stimulation of the cells for different periods of time as indicated in Figure 4B. Phosphorylation of ERK p44/42 was detected within five minutes of stimulation, and remained slightly elevated as long as two hours after the initial challenge (Figure $4 \mathrm{~B}$ and $4 \mathrm{C}$ ). In addition, the calcineurin-disrupting agent TEMPO impaired ERK phosphorylation (Figure 4D and 4E).

Next, we evaluated whether p38, an independent major MAPKs pathway, participated in $\beta$-glucan mediated IL-8 secretion from airway epithelial cells in response to PCBG (Figure 5). The specific pharmacological inhibitor of p38, SB202190, was administered prior to and throughout PCBG stimulations of $1 \mathrm{HAEo}^{-}$cells. Notably, SB202190 treated cells demonstrated significant reduction of IL-8 secretion in a dose-dependent manner, indicating the participation of p38 in the release of IL- 8 (Figure 5A). In addition, we further investigated the kinetics of p38 activation following PCBG stimulation. Phosphorylation of p38 was detected as early as 15 minutes following stimulation, and reached its peak after 30 minutes. Following one hour of PCBG stimulation, phosphorylation of p38 had returned to baseline levels (Figure $5 \mathrm{~B}$ and $5 \mathrm{C}$ ). These data verify differential kinetics of these two MAPK signaling pathways, with the activation of p38 being substantially slower than the phosphorylation of ERK p44/42.

Finally, we investigated whether another important member of the MAPK signaling family, JNK, was also involved in IL-8 secretion by airway epithelial cells following challenge with PCBG (Figure 6). The JNK inhibitor II, a pharmacological antagonist of JNK was used 


\section{A}

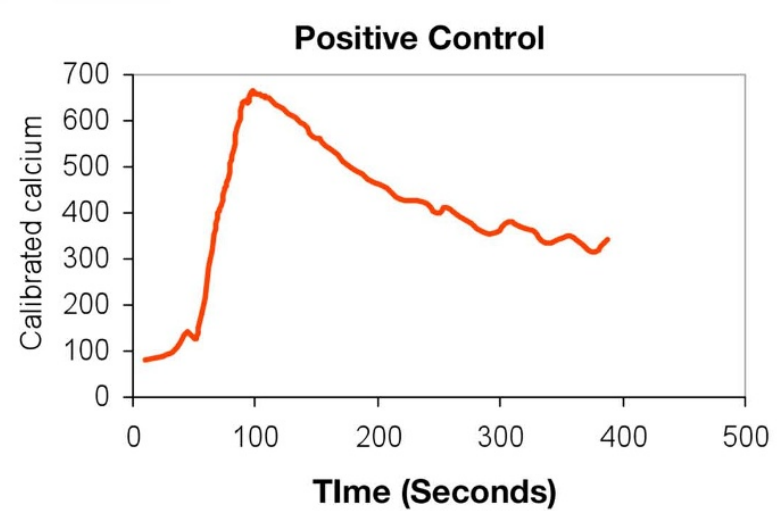

PCBG

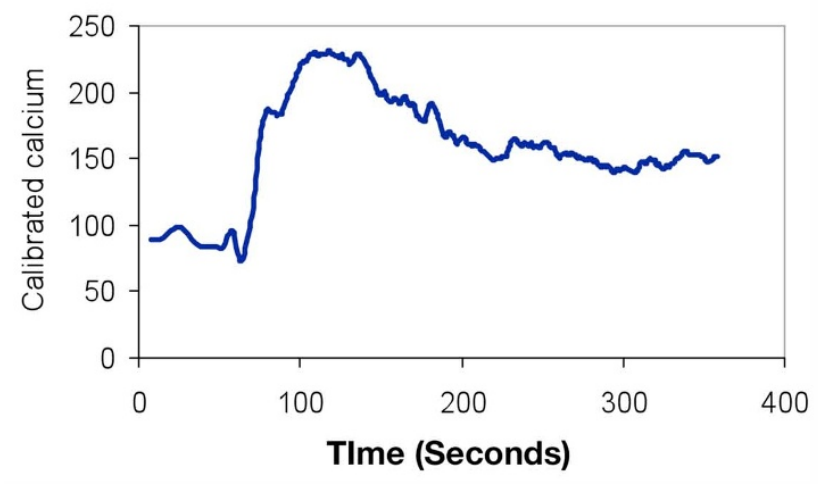

B

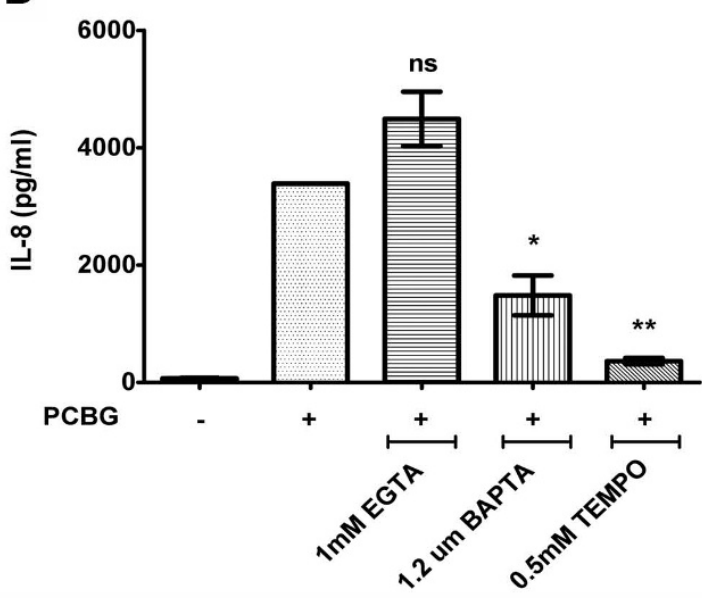

c

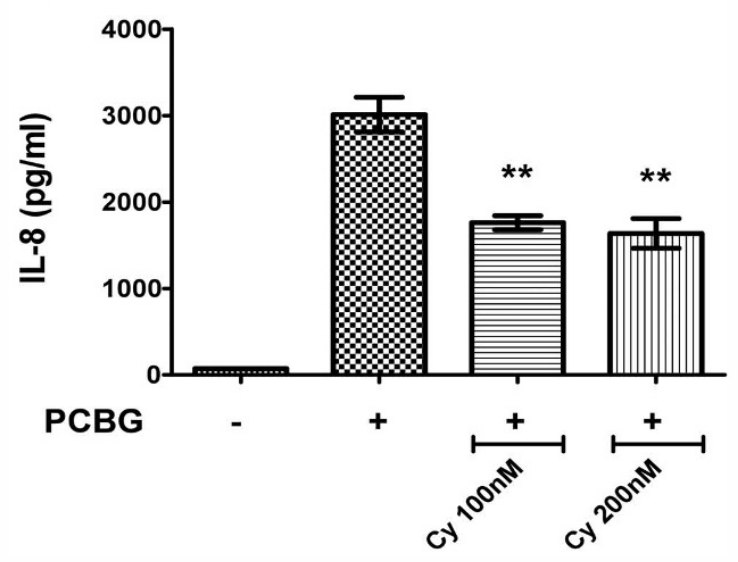

Figure 2 Intracellular calcium mobilization after PCBG stimulation. A. Airway epithelial cells (1HAEo-cells) were loaded with Fura-2AM and incubated with either $100 \mathrm{ug} / \mathrm{ml}$ of PCBG or with PAR-2 Peptide control $(100 \mu \mathrm{M})$ for the indicated times and transient intracellular calcium release monitored by video fluorescence imaging. B. In additional experiments, airway epithelial cells were incubated with $100 \mathrm{ug} / \mathrm{ml}$ of PCBG. For one hour prior to the addition of PCBG, the cells were preincubated with various calcium and calcineurin disrupting agents (EGTA, BAPTA, or TEMPO) at the concentration indicated. IL-8 secretion was measured by ELISA in the supernatant of the cells after eight hours of incubation. C. Finally, airway epithelial cells were incubated with $100 \mathrm{ug} / \mathrm{ml}$ of PCBG for eight hours in the presence of cyclosporine $A$ at the indicated concentration and IL-8 secretion measured by ELISA. Data were analyzed with one-way ANOVA and posttest Bonferroni comparison ( ${ }^{*}$ denotes $p<0.05 ;{ }^{* *}$ denotes $p<0.01$ ). The data shown are representative of three independent experiments.

prior to and through stimulation of 1HAEo-cells over PCBC for eight hours [46]. Interestingly, we did not detect any inhibition of IL-8 secretion in PCBG stimulated cells in the presence of the JNK-II inhibitor. To verify that the inhibitor was functionally active, we further analyzed phosphorylation of JNK in PCBG stimulated cells in the presence of JNK inhibitor II in comparison to cells that were stimulated with PCBG in the absence of the inhibitor, verifying that JNK phosphorylation was indeed greatly reduced (data not shown). Nevertheless, IL-8 secretion was not impacted by this inhibitor, indicating that the participation of ERK and p38 MAPK in airway epithelial cells stimulated with PCBG is specifically restricted to those pathways, and that JNK does not participate in this cytokine response.

\section{MAPK activation in PCBG stimulated 1HAEo- cells stimulates downstream NF-KB expression}

We have previously shown that MIP-2 neutrophil chemokine induced by PCBG in rodent primary lung epithelial cells is mediated by NF- $\mathrm{kB}$ activation (10). We next sought to determine whether MAPK activation following $\beta$-glucan stimulation of human $1 \mathrm{HAEo}^{-}$cells resulted in downstream NF-KB dependant activation (Figure 7). To test this, we evaluated whether PCBG induced ERK and p38 signaling resulted in NF- $\mathrm{KB}$ promoter dependent 


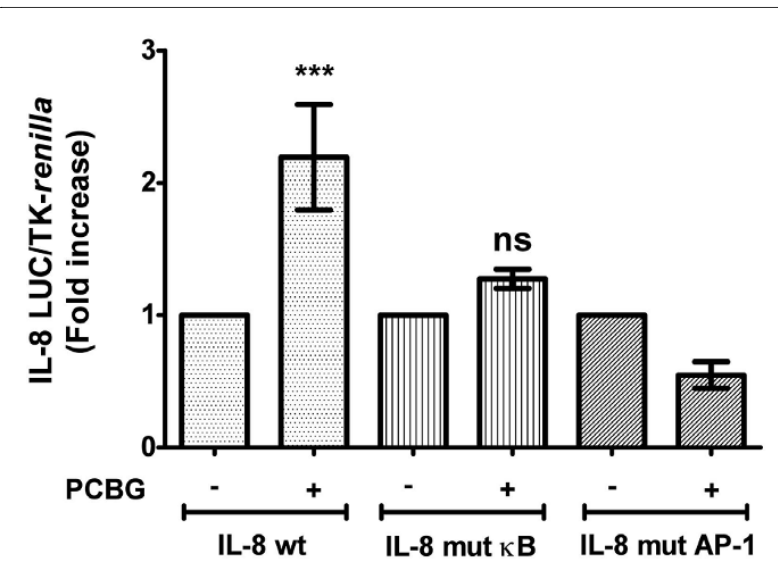

Figure 3 PCBG induced IL-8 expression requires NF-KB and AP-1 activation. 1HAEO- cells were transiently transfected with the IL-8 promoter (WT), the IL-8 promoter mutated at the NF-KB site (mut kB) or the IL-8 promoter mutated at the AP-1 site (mut AP-1). TK-renilla (10 ng) was co-transfected as an internal control as indicated in material and methods. Eighteen hours later, transfected $1 \mathrm{HAEO}$ - cells were challenged with $100 \mathrm{ug} / \mathrm{ml}$ of PCBG. After an additional eight hours of incubation, the cells were harvested and luciferase activities were measured. The IL-8 activity was normalized to Renilla luciferase activity (relative lights units). Data were analyzed with one-way ANOVA and posttest Bonferroni comparison (***denotes $p<0.01$ ). The data shown is the average of two independent experiments.

activation in $1 \mathrm{HAEo}^{-}$cells that were transiently transfected with an NF- $\mathrm{kB}$-dependent luciferase reporter plasmid. Prior to PCBG stimulation, the $1 \mathrm{HAEo}^{-}$cells were incubated with either; the PD98059, SB202190, or the JNK inhibitor II. Notably, pre-incubation of the cells with either PD98059 or SB202190 significantly reduced NF-kB dependent transcriptional activity in PCBG stimulated cells. However, the addition of JNK inhibitor II again had no effect on transcriptional activity related to NF- $\mathrm{kB}$. These data suggest that PCBG mediated MAPKs activation results in downstream NF- $\mathrm{kB}$-dependent transcriptional activation in target airway epithelial cells.

\section{Inhibition of glycosphingolipids synthesis further impairs IL-8 released by airway epithelial cells stimulated with PCBG}

Previous data from our laboratory indicate that PCBG requires the glycosphingolipid lactosylceramide to induce MIP-2 release in murine epithelial cells [17,47]. We, therefore, sought to determine whether IL- 8 secretion by PCBG in these human airway cells was also dependent on the presence of glycosphingolipids. To accomplish this, we evaluated IL-8 secretion in PCBG stimulated cells in the presence of PDMP, a potent glycosphingolipid synthesis inhibitor. Serum free media cultivated cells were treated with PDMP for 3 days prior to stimulation with PCBG. IL-8 release from $\beta$-glucan stimulated airway epithelial cells treated with the glycosphingolipid inhibitor was significantly decreased compared to non-treated cells (Figure 8A). We further investigated the effect of PDMP on ERK phosphorylation. Cells were cultured with media alone or in the presence of PDMP prior to activation with PCBG. Total cell lysates were analyzed for phospho-p44/42 by immunoblotting (Figure $8 \mathrm{~B}$ and $8 \mathrm{C}$ ). The phosphorylation of ERK p44/42 was reduced to baseline in cells treated with PDMP compared with non-treated cells. Taken together, these data strongly support our findings that glycosphingolipids are important for PCBG mediated ERK activation and subsequent IL-8 secretion by airway epithelial cells in response to PCBG.

\section{Discussion}

Tissue inflammation is an essential component of host defense against infection, however, exaggerated inflammatory response can be extremely deleterious to the host. Considerable evidence reveals this to be particularly true for Pneumocystis pneumonia. Early studies from our laboratory, as well as from other investigators have documented that death and respiratory failure in patients with Pneumocystis pneumonia is largely related to the intense inflammatory reaction induced by the infection rather than direct toxic effects of the fungus [3-5,9,30]. Many patients with this infection present with intense neutrophilic and CD8 lymphocytic infiltration in the lungs and associated impaired oxygen exchange. What induces the exaggerated recruitment of inflammatory cells in these patients remains poorly understood. These studies were undertaken to address the molecular mechanisms, which regulates the potent neutrophil chemoattractant factor, IL-8 in airway epithelial cells challenged with the potent pro-inflammatory cell wall component of Pneumocystis $\beta$-glucan.

Studies from our lab have documented the inflammatory properties of PCBG, and have revealed that this carbohydrate-rich cell wall fraction is capable of inducing specific chemokines and cytokines in cells such as macrophages, dendritic cells (DC) and alveolar epithelial cells $[11,12,17,18]$. Airway epithelial cells are the first cells to come into contact with inhaled pulmonary pathogens. Contrary to earlier beliefs that alveolar epithelial cells were only involved in gas exchange, emerging evidence has documented the importance of these cells as a rich source of inflammatory mediators, particularly chemokines. We have specifically demonstrated that rodent alveolar epithelial cells undergo NF-kB mediated MIP-2 release when challenged with Pneumocystis $\beta$-glucans. In this regard, airway epithelial cells exhibit greater potency than alveolar macrophages challenged with this cell wall component $(10,19)$. In the present study, we further demonstrate that human airway epithelial cells secrete significant amounts of IL-8, the human homologue of MIP-2, in response to Pneumocystis cell wall $\beta$-glucan. We have fur- 


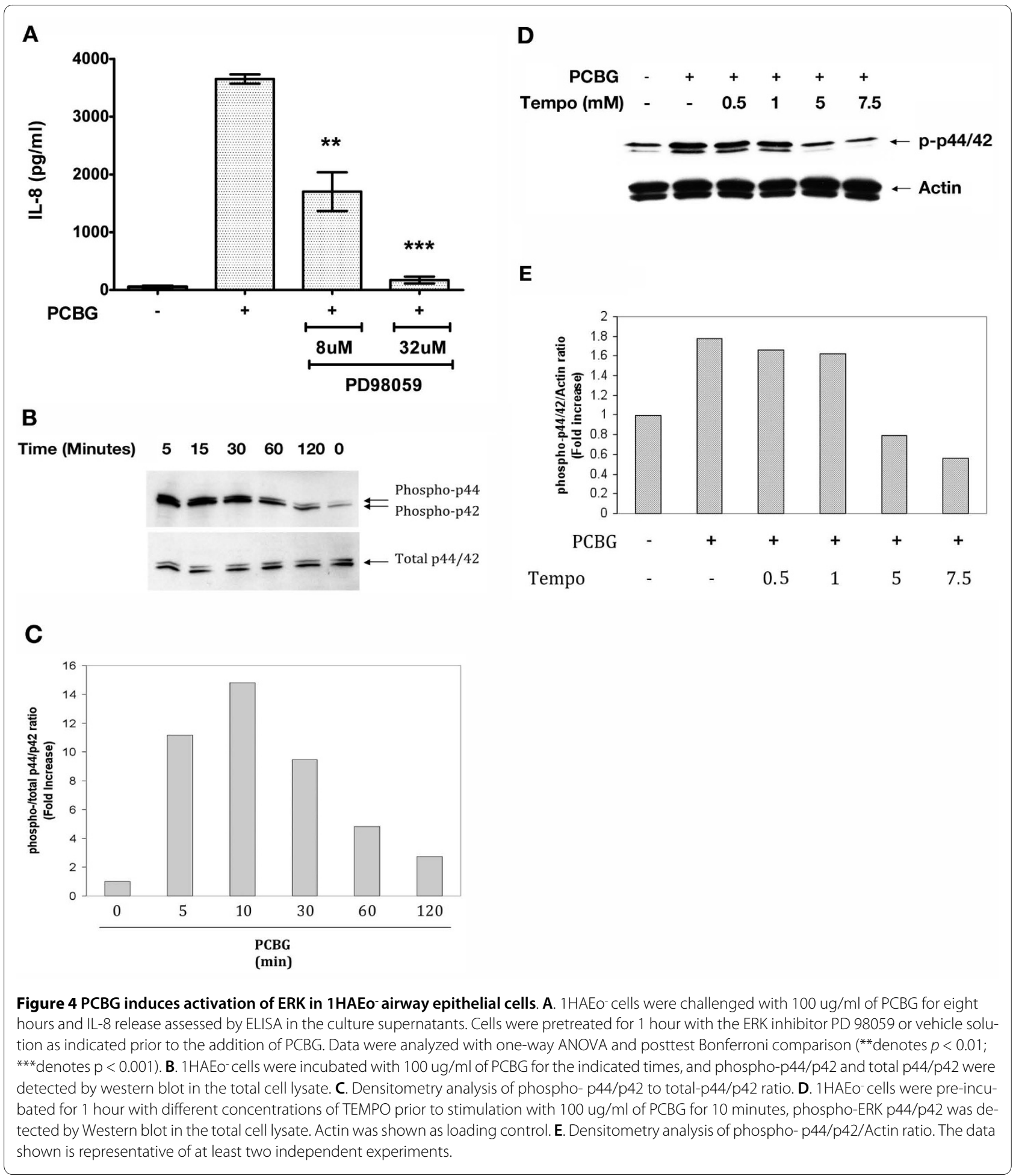

ther observed that airway epithelial cells mobilize intracellular calcium within seconds following $\beta$-glucan stimulation. This intra-calcium flux initiates the activation of the two major MAPKs pathways, ERK and p38, and subsequent activation of AP-1 and NF- $\mathrm{kB}$, resulting in the release of IL-8. Finally, we demonstrated that inhi- bition of glycosphingolipids synthesis significantly impairs the IL- 8 response of these cells, suggesting an important role for surface membrane glycosphingolipids conferring inflammatory activation.

Glycosphingolipids, most notably lactosylceramide, have been proposed as receptors for fungal $\beta$-glucans, 


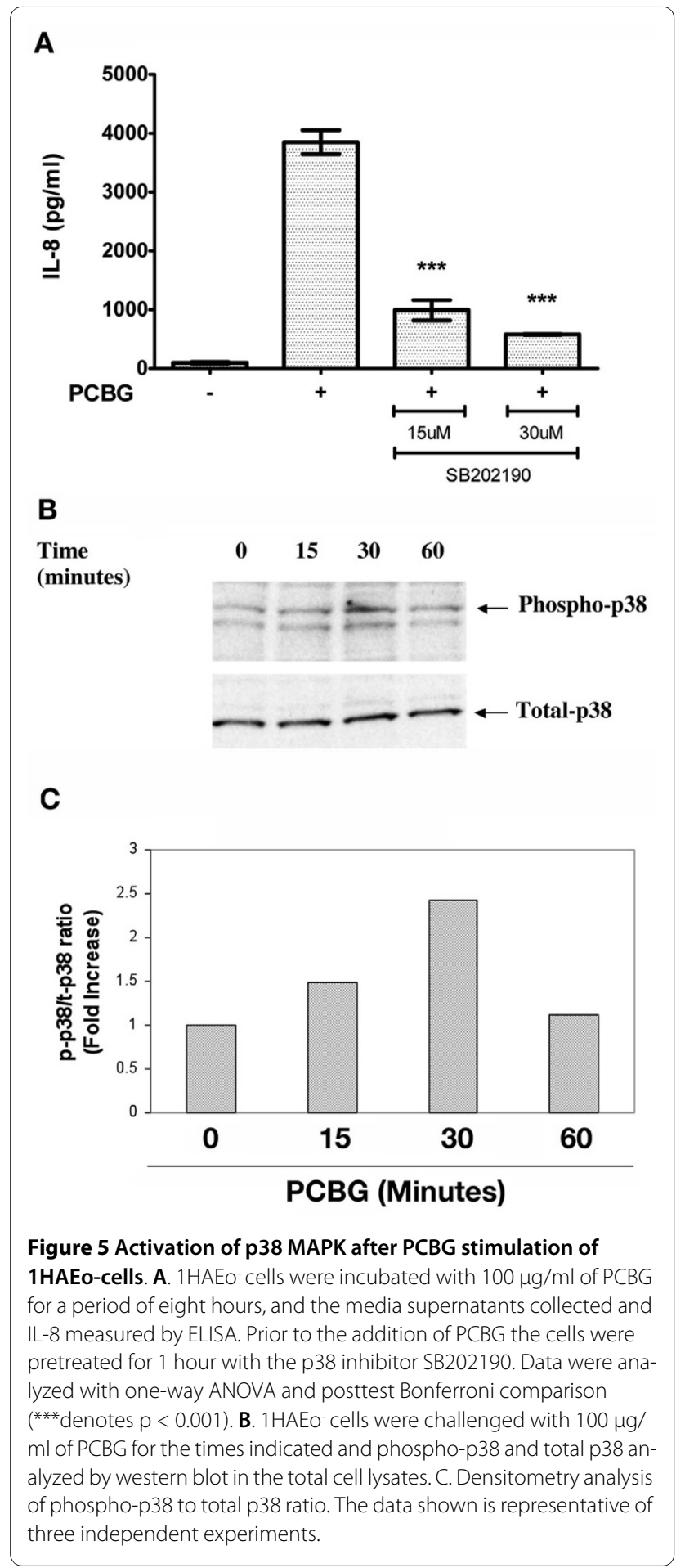

and have been of particular interest in cellular activation mediated by Pneumocystis $(15,16)$. In the present study, we demonstrated that treatment of human airway epithelial cells with PDMP, a glycosphingolipid synthesis inhibitor, dramatically reduced the ability of Pneumocystis $\beta$ glucans to stimulate IL- 8 release, strongly indicating that glycosphingolipids are important components initiating

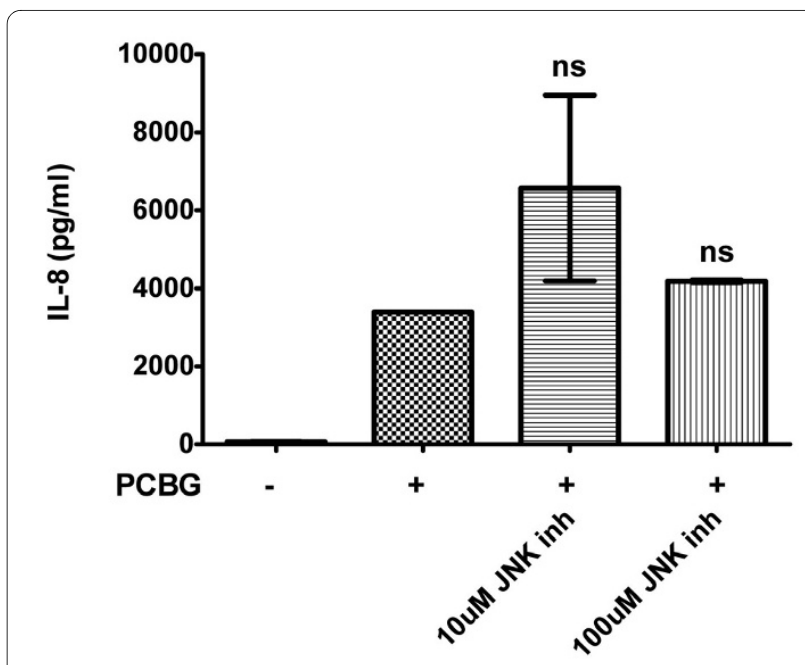

Figure 6 IL-8 production by PCBG activated cells is not impaired in the presence of a pharmacological inhibitor of JNK-II. 1 HAEOcells were incubated with $100 \mathrm{ug} / \mathrm{ml}$ of PCBG for a period of eight hours. Prior to the addition of PCBG, the cells were preincubated for one hour with JNK Inhibitor II at the concentration indicated. IL-8 secretion was measured by ELISA in the media supernatant of the cells, Data were analyzed with one-way ANOVA and posttest Bonferroni comparison (not significantly different, $p>0.05$ ). The data shown is representative of two independent experiments.

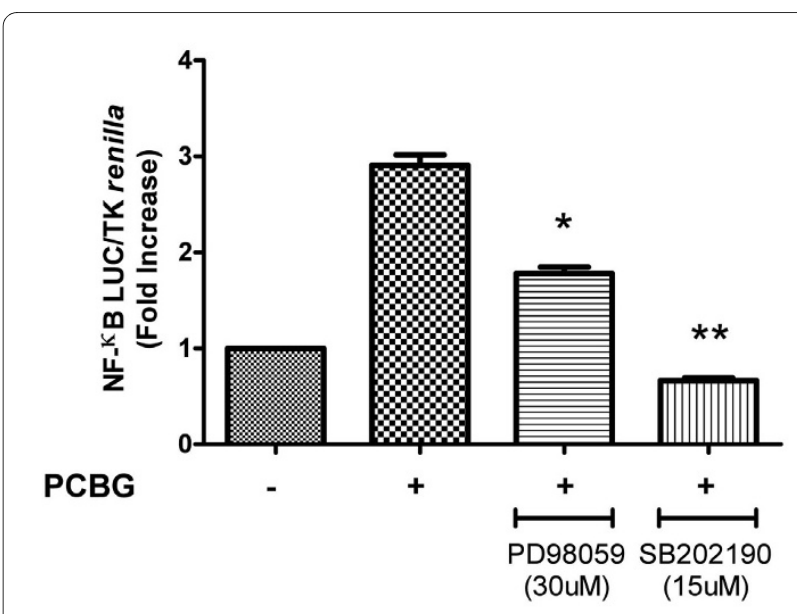

Figure $7 \mathrm{NF}-\mathrm{KB}$ activation is impaired in the presence of MAPKs inhibitors and an intra-calcium chelator, but not in the presence of JNK inhibitor. $1 \mathrm{HAEO}^{-}$cells were transiently transfected with the NF-KB reporter (50 $\mathrm{ng}$ ) and TK-renilla (10 $\mathrm{ng}$ ) as indicated in the Material and Methods. Eighteen hours later, transfected $1 \mathrm{HAEO}^{-}$cells were challenged with $100 \mu \mathrm{g} / \mathrm{ml}$ of PCBG, prior stimulation the cells were preincubated for $1 \mathrm{~h}$ with the different inhibitors. Eight hours later, the cells were harvested and luciferase activities were measured. The NF-KB activity was normalized to Renilla luciferase activity (relative lights units). Data were analyzed with one-way ANOVA and posttest Bonferroni comparison ( ${ }^{*}$ denotes $p<0.05$; ${ }^{* *}$ denotes $p<0.01$ ). The data shown is representative of three independent experiments. 


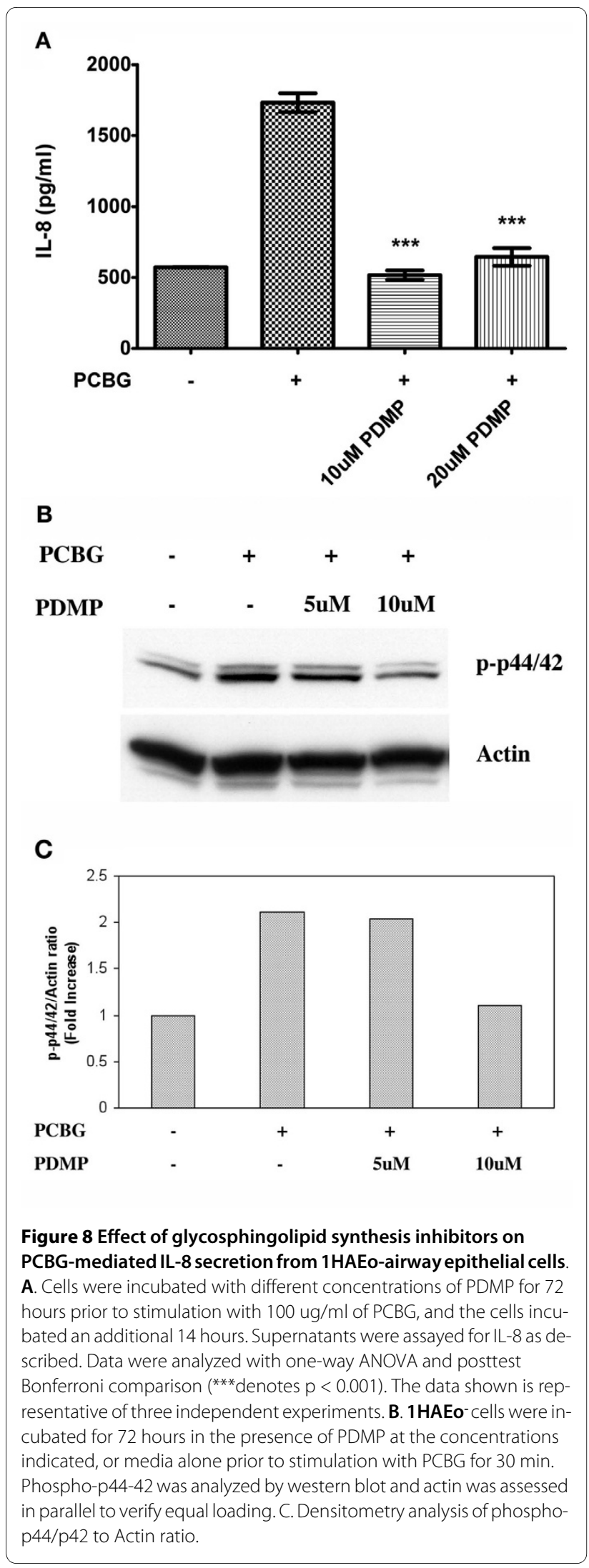

epithelial cell signaling. In the present study, we further observed that intracellular calcium mobilization, as well as activation of two major MAPK pathways (ERK and p38), also participate in epithelial cells responses to PCBG.

Intracellular calcium mobilization appears necessary for IL-8 secretion, since PCBG does not activate airway epithelial cells in the presence of the intracellular calcium chelator BAPTA/AM or the calcineurin inhibitor TEMPO. This early intracellular mobilization of calcium acts through additional second messengers to induce activation of the ERK and p38 MAPK pathways. Interestingly, these two pathways are likely stimulated through unique mechanisms, since their kinetics of activation were significantly different. While ERK p42/44 was phosphorylated within five minutes of stimulation, p38 reach its peak phosphorylation after 30 minutes. Ultimately, ERK and p38 pathways were both found to impact downstream NF- $\mathrm{kB}$ activation at the transcriptional level.

In contrast, we did not observe any decrease in IL-8 levels nor NF- $\mathrm{kB}$ transcriptional activation in the presence of the specific pharmacological inhibitor of JNK, suggesting that JNK does not participate in PCBG induced cell stimulation. Recently, an interesting report by Wang and coworkers demonstrated that whole Pneumocystis induced the release of MCP-1 from alveolar epithelial cells in a JNK-dependent fashion that did not appear to require $\beta$-glucan [48]. The study of Wang and colleagues utilized $\beta$-glucan derived from $S$. cerevisiae [48]. While we observed some minimal activation of epithelial cells by Saccharomyces $\beta$-glucan, PCBG was shown to be far more potent in stimulating the epithelial cells in a JNK independent manner in our hands.

The observations of our current study are comparable to those of Slevogt and coworkers, who noted activation of ERK and p38 but not participation of JNK in Moroxella catarrhalis induced IL-8 production by epithelial cells [49]. Interestingly, other studies have revealed differing patterns of MAP activation in response to other microorganisms. For instance, Lamont and coworkers has shown that Porphyromonas gingivalis infection of epithelial cells is associated with JNK activation, down regulation of ERK and NF- $\mathrm{KB}$ activation, and decrease of IL-8 expression [50]. These studied support the notion that speciesspecific stimuli result in specific, and often differing, cellular IL-8 responses. In the case of Pneumocystis, two predominant pathways appear to augment IL- 8 responses and neutrophilic recruitment in this pneumonia.

Regulation of IL- 8 transcription is mediated by various transcription factors including NF-kB, AP-1, and NF-IL6 , which appear to be both stimuli and cell type specific [51]. For instance, adequate induction of IL- 8 by TNF- $\alpha$ stimulated epithelial cells requires AP-1 and NF- $\mathrm{KB}$ bind- 
ing activity to the IL- 8 promoter, while AP-1 binding activity does not appear to be necessary in TNF- $\alpha$ stimulated endothelial cells [43]. This same group of investigators also demonstrated that AP-1 binding, and not the NF- $\mathrm{KB}$, is critical for IL-8 expression by $\mathrm{H}_{2} \mathrm{O}_{2}$ stimulated epithelial cells [43]. The current studies demonstrate that IL-8 secretion and gene transcription induced by PCBG in human airway epithelial cells requires the integrity of NF- $\mathrm{KB}$ and AP-1 binding sites. This is noteworthy, because distinct AP-1 dimers may selectively interact with various NF- $\mathrm{kB}$ subunits and synergistically act to augment IL-8 expression. Such interaction have been demonstrated to occur in respiratory syncytial virus (RSV) induced IL-8 expression [41]. Indeed, in RSV infected cells, AP-1 cooperates preferentially with NF- $\mathrm{kB}$, while in TNF- $\alpha$ stimulated cells NF-IL-6 interacts with NF- $\kappa B$ [41]. Based on these observations, we postulate that alteration of the binding between these various transcription factor subunits may help to initially promote IL8 secretion in Pneumocystis pneumonia and subsequently to control neutrophil inflammation in this infection.

\section{Conclusion}

In summary, our investigations have demonstrated that Pneumocystis cell wall $\beta$-glucans induce inflammatory response in human airway epithelial cells. IL-8 secretion by these cells involves membrane glycosphingolipid receptors and the intracellular mobilization of calcium, with subsequent phosphorylation of MAPKs pathways including ERK and p38. These events lead to downstream activation of the NF- $\mathrm{kB}$ and AP-1 transcription factors and ultimately to IL- 8 release. Abrogation of either one or these MAPK pathways or these transcription factors results in a blunted IL-8 response. Better knowledge of the molecular mechanisms regulating chemokine generation will be essential to understand the recruitment of inflammatory cells to the lung during Pneumocystis pneumonia, and to design new treatment strategies for the exuberant lung inflammation that accompanies this infection.

\section{Competing interests}

The authors declare that they have no competing interests.

\section{Authors' contributions}

EMC performed the cytokine, signal transduction, and promoter assays and participated in drafting the manuscript. JDL assisted with the signal transduction assays and cell culture work. AX participated in the calcium signaling studies. MW participated in its design and coordination of the calcium experiments. AHL participated in the overall experimental design concept, review and interpretation of data, preparation of the manuscript and secured all funding for these studies. All authors read and approved the final manuscript.

\section{Acknowledgements}

These studies were funded by the Mayo Foundation and NIH grants R01HL62150 and R01-HL55934 to AHL. EMC was supported by funds from Mayo Foundation. We thank Zvezdana Vuk-Pavlovic' and Joshua Burgess for many helpful discussions. We further acknowledge the efforts of Deanne Hebrink and Joseph Standing in the generation of the Pneumocystis carinii organisms and the Pneumocystis $\beta$-glucan preparations used in these studies. Finally, we appreciate the efforts of Ted Kottom for invaluable technical support for these studies.

\section{Author Details}

From the Thoracic Diseases Research Unit, Division of Pulmonary Critical Care and Internal Medicine, Department of Medicine Mayo Clinic and Foundation, Rochester, Minnesota, 55905, USA

Received: 21 October 2009 Accepted: 13 July 2010

Published: 13 July 2010

\section{References}

1. Kaplan JE, Hanson D, Dworkin MS, Frederick T, Bertolli J, Lindegren ML, Holmberg S, Jones JL: Epidemiology of human immunodeficiency virus-associated opportunistic infections in the United States in the era of highly active antiretroviral therapy. Clin Infect Dis 2000, 30(Suppl 1):S5-14.

2. Russian DA, Levine SJ: Pneumocystis carinii pneumonia in patients without HIV infection. Am J Med Sci 2001, 321(1):56-65.

3. Thomas CF Jr, Limper AH: Pneumocystis pneumonia. N Engl J Med 2004, 350(24):2487-2498.

4. Limper AH, Offord KP, Smith TF, Martin WJ: Pneumocystis carinii pneumonia. Differences in lung parasite number and inflammation in patients with and without AIDS. Am Rev Respir Dis 1989, 140(5):1204-1209.

5. Wright TW, Gigliotti F, Finkelstein JN, McBride JT, An CL, Harmsen AG: Immune-mediated inflammation directly impairs pulmonary function contributing to the pathogenesis of Pneumocystis carinii pneumonia. J Clin Invest 1999, 104(9):1307-1317.

6. Wright TW, Gigliotti F, Finkelstein JN, McBride JT, An CL, Harmsen AG: Immune-mediated inflammation directly impairs pulmonary function contributing to the pathogenesis of Pneumocystis carinii pneumonia. J Clin Invest 1999, 104(9):1307-1317.

7. Bhagwat SP, Gigliotti F, Xu H, Wright TW: Contribution of T cell subsets to the pathophysiology of Pneumocystis-related immunorestitution disease. Am J Physiol Lung Cell Mol Physiol 2006, 291 (6):L1256-1266.

8. Gigliotti F, Crow EL, Bhagwat SP, Wright TW: Sensitized CD8+ T cells fail to control organism burden but accelerate the onset of lung injury during Pneumocystis carinii pneumonia. Infect Immun 2006, 74(11):6310-6316.

9. Mason GR, Hashimoto CH, Dickman PS, Foutty LF, Cobb CJ: Prognostic implications of bronchoalveolar lavage neutrophilia in patients with Pneumocystis carinii pneumonia and AIDS. Am Rev Respir Dis 1989, 139(6):1336-1342.

10. Limper AH, Thomas CF Jr, Anders RA, Leof EB: Interactions of parasite and host epithelial cell cycle regulation during Pneumocystis carinii pneumonia. J Lab Clin Med 1997, 130(2):132-138.

11. Vassallo R, Standing JE, Limper AH: Isolated Pneumocystis carinii cell wall glucan provokes lower respiratory tract inflammatory responses. J Immunol 2000, 164(7):3755-3763.

12. Lebron F, Vassallo R, Puri V, Limper AH: Pneumocystis carinii cell wall beta-glucans initiate macrophage inflammatory responses through NF-kappaB activation. J Biol Chem 2003, 278(27):25001-25008. Epub 22003 Apr 25025

13. Limper AH, Edens $M$, Anders RA, Leof EB: Pneumocystis carinii inhibits cyclin-dependent kinase activity in lung epithelial cells. J Clin Invest 1998, 101(5):1148-1155

14. Limper AH: Parasitic adherence and host responses in the development of Pneumocystis carinii pneumonia. Semin Respir Infect 1991, 6(1):19-26.

15. Krajicek BJ, Thomas CF Jr, Limper AH: Pneumocystis pneumonia: current concepts in pathogenesis diagnosis, and treatment. Clin Chest Med 2009, 30(2):265-278. vi

16. McCann F, Carmona E, Puri V, Pagano RE, Limper AH: Macrophage internalization of fungal beta-glucans is not necessary for initiation of related inflammatory responses. Infect Immun 2005, 73(10):6340-6349.

17. Evans SE, Hahn PY, McCann F, Kottom TJ, Pavlovic ZV, Limper AH: Pneumocystis Cell Wall \{beta\}-Glucans Stimulate Alveolar Epithelial Cell Chemokine Generation through Nuclear Factor-\{kappa\}BDependent Mechanisms. Am J Respir Cell Mol Biol 2005, 32(6):490-497. 
18. Hahn PY, Evans SE, Kottom TJ, Standing JE, Pagano RE, Limper AH: Pneumocystis carinii cell wall beta-glucan induces release of macrophage inflammatory protein-2 from alveolar epithelial cells via a lactosylceramide-mediated mechanism. J Biol Chem 2003, 278(3):2043-2050. Epub 2002 Nov 2044

19. Ratner AJ, Bryan R, Weber A, Nguyen S, Barnes D, Pitt A, Gelber S, Cheung A, Prince A: Cystic fibrosis pathogens activate Ca2+-dependent mitogen-activated protein kinase signaling pathways in airway epithelial cells. J Bio/ Chem 2001, 276(22):19267-19275.

20. Gewirtz AT, Rao AS, Simon PO Jr, Merlin D, Carnes D, Madara JL, Neish AS: Salmonella typhimurium induces epithelial IL-8 expression via $\mathrm{Ca}(2+)-$ mediated activation of the NF-kappaB pathway. J Clin Invest 2000, 105(1):79-92.

21. Segal E: Pathogenesis of human mycoses: role of adhesion to host surfaces. Microbio/ Sci 1987, 4(11):344-347.

22. Douglas LJ: Adhesion of Candida species to epithelial surfaces. Crit Rev Microbiol 1987, 15(1):27-43.

23. Brown GD, Gordon S: Immune recognition. A new receptor for betaglucans. Nature 2001, 413(6851):36-37.

24. Carmona EM, Vassallo R, Vuk-Pavlovic Z, Standing JE, Kottom TJ, Limper $\mathrm{AH}$ : Pneumocystis cell wall beta-glucans induce dendritic cell costimulatory molecule expression and inflammatory activation through a Fas-Fas ligand mechanism. J Immuno/ 2006, 177(1):459-467.

25. Limper $\mathrm{AH}$, Hoyte JS, Standing JE: The role of alveolar macrophages in Pneumocystis carinii degradation and clearance from the lung. J Clin Invest 1997, 99(9):2110-2117

26. Cozens AL, Yezzi MJ, Chin L, Simon EM, Friend DS, Gruenert DC: Chloride ion transport in transformed normal and cystic fibrosis epithelial cells. Adv Exp Med Biol 1991, 290:187-194. discussion 194-186

27. Trushin SA, Pennington KN, Algeciras-Schimnich A, Paya CV: Protein kinase $C$ and calcineurin synergize to activate lkappaB kinase and NFkappaB in T lymphocytes. J Biol Chem 1999, 274(33):22923-22931.

28. Shimotake TK, Izhar FM, Rumilla K, Li J, Tan A, Page K, Brasier AR, Schreiber $M D$, Hershenson MB: Interleukin (IL)-1 beta in tracheal aspirates from premature infants induces airway epithelial cell IL-8 expression via an NF-kappa B dependent pathway. Pediatr Res 2004, 56(6):907-913. Epub 2004 Oct 2020

29. White TA, Kannan MS, Walseth TF: Intracellular calcium signaling through the CADPR pathway is agonist specific in porcine airway smooth muscle. Faseb J 2003, 17(3):482-484

30. Beck JM, Rosen MJ, Peavy HH: Pulmonary complications of HIV infection. Report of the Fourth NHLBI Workshop. Am J Respir Crit Care Med 2001, 164(11):2120-2126.

31. Adamo R, Sokol S, Soong G, Gomez MI, Prince A: Pseudomonas aeruginosa flagella activate airway epithelial cells through asialoGM1 and toll-like receptor 2 as well as toll-like receptor 5. Am J Respir Cell Mol Biol 2004, 30(5):627-634. Epub 2003 Nov 2007

32. Mellstrom B, Naranjo JR: Mechanisms of $\mathrm{Ca} 2+)$-dependent transcription. Curr Opin Neurobiol 2001, 11(3):312-319.

33. Lindenboim L, Haviv R, Stein R: Inhibition of drug-induced apoptosis by survival factors in PC12 cells. J Neurochem 1995, 64(3):1054-1063.

34. Dieter $P$, Fitzke E, Duyster J: BAPTA induces a decrease of intracellular free calcium and a translocation and inactivation of protein kinase $C$ in macrophages. Biol Chem Hoppe Seyler 1993, 374(3):171-174.

35. Nelson PA, Akselband Y, Kawamura A, Su M, Tung RD, Rich DH, Kishore V, Rosborough SL, DeCenzo MT, Livingston DJ, Harding MW:

Immunosuppressive activity of [MeBm2t]1-, D-diaminobutyryl-8-, and D-diaminopropyl-8-cyclosporin analogues correlates with inhibition of calcineurin phosphatase activity. J Immuno/ 1993, 150(6):2139-2147.

36. Nakamura H, Yoshimura K, Jaffe HA, Crystal RG: Interleukin-8 gene expression in human bronchial epithelial cells. J Biol Chem 1991, 266(29):19611-19617.

37. Brasier AR, Jamaluddin M, Casola A, Duan W, Shen Q, Garofalo RP: A promoter recruitment mechanism for tumor necrosis factor-alphainduced interleukin-8 transcription in type II pulmonary epithelial cells. Dependence on nuclear abundance of Rel A, NF-kappaB1, and cRel transcription factors. J Biol Chem 1998, 273(6):3551-3561.

38. Mukaida N, Mahe Y, Matsushima K: Cooperative interaction of nuclear factor-kappa B- and cis-regulatory enhancer binding protein-like factor binding elements in activating the interleukin- 8 gene by proinflammatory cytokines. J Bio/ Chem 1990, 265(34):21128-21133.
39. Stein B, Baldwin AS Jr: Distinct mechanisms for regulation of the interleukin-8 gene involve synergism and cooperativity between C/ EBP and NF-kappa B. Mol Cell Biol 1993, 13(11):7191-7198.

40. Matsusaka T, Fujikawa K, Nishio Y, Mukaida N, Matsushima K, Kishimoto T, Akira S: Transcription factors NF-IL6 and NF-kappa B synergistically activate transcription of the inflammatory cytokines, interleukin 6 and interleukin 8. Proc Natl Acad Sci USA 1993, 90(21):10193-10197.

41. Kunsch C, Rosen CA: NF-kappa B subunit-specific regulation of the interleukin-8 promoter. Mol Cell Biol 1993, 13(10):6137-6146.

42. Fiedler MA, Wernke-Dollries K, Stark JM: Mechanism of RSV-induced IL-8 gene expression in A549 cells before viral replication. Am J Physiol 1996, 271 (6 Pt 1):L963-971.

43. Lakshminarayanan V, Drab-Weiss EA, Roebuck KA: H2O2 and tumor necrosis factor-alpha induce differential binding of the redoxresponsive transcription factors $A P-1$ and NF-kappaB to the interleukin-8 promoter in endothelial and epithelial cells. J Biol Chem 1998, 273(49):32670-32678.

44. Schmeck B, Zahlten J, Moog K, van Laak V, Huber S, Hocke AC, Opitz B, Hoffmann E, Kracht M, Zerrahn J, Hammerschmidt S, Rosseau S, Suttorp N, Hippenstiel S: Streptococcus pneumoniae-induced p38 MAPKdependent phosphorylation of RelA at the interleukin-8 promotor. $J$ Biol Chem 2004, 279(51):53241-53247. Epub 52004 Oct 53213

45. Griego SD, Weston CB, Adams JL, Tal-Singer R, Dillon SB: Role of p38 mitogen-activated protein kinase in rhinovirus-induced cytokine production by bronchial epithelial cells. J Immuno/ 2000, 165(9):5211-5220.

46. Bennett BL, Sasaki DT, Murray BW, O'Leary EC, Sakata ST, Xu W, Leisten JC, Motiwala A, Pierce S, Satoh Y, Bhagwat SS, Manning AM, Anderson DW: SP600125, an anthrapyrazolone inhibitor of Jun N-terminal kinase. Proc Natl Acad Sci USA 2001, 98(24):13681-13686.

47. Hahn PY, Limper AH: Pneumocystis carinii beta-glucan induces release of macrophage inflammatory protein-2 from primary rat alveolar epithelial cells via a receptor distinct from CD11b/CD18. J Eukaryot Microbiol 2001:157S

48. Wang J, Gigliotti F, Bhagwat SP, Maggirwar SB, Wright TW: Pneumocystis stimulates MCP-1 production by alveolar epithelial cells through a JNKdependent mechanism. Am J Physiol Lung Cell Mol Physiol 2007, 292(6):L1495-1505.

49. Slevogt H, Schmeck B, Jonatat C, Zahlten J, Beermann W, van Laak V, Opitz B, Dietel S, N'Guessan PD, Hippenstiel S, Suttorp N, Seybold J: Moraxella catarrhalis induces inflammatory response of bronchial epithelial cells via MAPK and NF-kappaB activation and histone deacetylase activity reduction. Am J Physiol Lung Cell Mol Physiol 2006, 290(5):L818-826.

50. Watanabe K, Yilmaz O, Nakhjiri SF, Belton CM, Lamont RJ: Association of mitogen-activated protein kinase pathways with gingival epithelial cell responses to Porphyromonas gingivalis infection. Infect Immun 2001, 69(11):6731-6737.

51. Roebuck KA: Regulation of interleukin-8 gene expression. J Interferon Cytokine Res 1999, 19(5):429-438.

doi: 10.1186/1465-9921-11-95

Cite this article as: Carmona et al., Pneumocystis cell wall ?-glucan stimulates calcium-dependent signaling of IL-8 secretion by human airway epithelial cells Respiratory Research 2010, 11:95

\section{Submit your next manuscript to BioMed Centra and take full advantage of:}

- Convenient online submission

- Thorough peer review

- No space constraints or color figure charges

- Immediate publication on acceptance

- Inclusion in PubMed, CAS, Scopus and Google Scholar

- Research which is freely available for redistribution 